\title{
PIEDRAS, NIEVE Y AGUA EN EL SANTUARIO ANDINO DE QUILIUR RIT'I
}

\author{
Efrain Cáceres Chalco
}

\section{Resumen}

En el santuario andino de Quyllur Ril'i hay elementos que cobran relevancia vital para los peregrinos. Estos elementos potencialmente son el agua, la nieve y las piedras que personifican al Apu, una de las deidades andinas del Kay Pacha [este mundo], que intervienen en la solución de los problemas de salud y bienestar de los runas andinos.

Cada uno de estos elementos tiene una significación simbólica en la conciencia de los peregrinos y son ejes representativos de la fe de los peregrinos.

La manjpulación, la compenetración y fusión con estos elementos, muestra a los nunas como miembros de una cultura apegada a su fe ancestral, basados en las actividades agrícola-ganaderas, y de compenetración con la naturaleza andina.

Palabras clave: Piedras / Nieve / Agua / Culura / Religiosidad Andina 


\section{QUYLLUR RIT'I: ESPACIO SAGRADO DE REGREAGIÓN Y RESISTENGIA GULTURAL ANDINA}

El carácter movilizador, concentrador en espacios y tiempos fijados por el calendario ritual de la cultura indígena andina, determina peregrinaciones y este es un fenómeno central en la religiosidad indígena andina; es decir, el fundamento básico de esta religiosidad viene a ser la manifestación del movimiento y traslado, por la concepción de vida que contienen los elementos de su cosmos, todo tiene vida...

Por lo tanto, el principio de traslación se plasma en el cambio de espacio en un tiempo definido y determinado por lo sagrado de la naturaleza, expresado en su desarrollo cíclico que le da al runa indígena andino la visión del tiempo circular. El traslado no solo es del yo personal, sino es con toda su pertenencia y toda su vida o kazesaynin.

En el sur andino se cuenta con varios espacios sagrados, a los que se denominan santuarios y uno de los más importantes es Quyllur Rit $i^{1}$. Su importancia la miden algunos autores por la cantidad de peregrinos concentrados por este espacio sagrado: 30,000, según Carlos Flores; 10,000 , según David Gow y 50,000, según el especial de El Nuevo Herald de EE. UU. (29-041990) Pero lo cierto es que, cada año durante tres días antes de la fiesta de Corpus Christi, se realiza esta peregrinación al Taytacha Quyllur Rit'i. Este espacio sagrado se halla a $40 \mathrm{~km}$ de Ocongate, pueblo perteneciente a la provincia de Quispicanchi y está situado aproximadamente a 4,900 $\mathrm{msnm}$.

El lugar del santuario se halla en las comunidades indígenas andinas de Mawayani y Tayankani, que formaban parte de la Cooperativa de Producción de Lauramarca (Flores, Carlos, 1987: 129), cooperativa ya disuelta, habiendo retornado sus tierras y propiedades a la comunidad andina de Mawayani.

Por la considerable altura del santuario de Quyllur Rit'i se puede colegir que los indígenas andinos gozan de las bondades de la naturaleza [pacha mama = madre tierra], subiendo a los apus [deidades de altura o nevados] o montes más elevados en peregrinación. El tamaño y la altura de la montaña significan psicológicamente la personalidad madura, este aspecto lo advertimos en los trabajos de Carl Jung (1994:24), la montaña significa la meta del peregrinaje y el ascenso, por lo cual corresponde psicológicamente con frecuencia al yo, y el yo de los runas simboliza pleno reconocimiento de sí mismo, como valor e identidad cultural integrado a su medio. Por tal razón, los runas indígenas andinos, dialogan permanentemente con la naturaleza a quien consideran como un acompañante de infortunio.

Esta peregrinación es muy importante por la participación mayoritaria de indígenas andinos, los que últimamente ven crecer el número de otros sectores como el urbano, pero que ingresan a la dinámica de la peregrinación que está delineada con la lógica y consistencia interna del pensamiento y la cosmovisión andina, que para algunos se presenta como algo incomprensible, irracional o complejo.

A través de este artículo no pretendemos describir los pasosylasritualidades de la peregrinación porque existen muchos trabajos que la desarrollan magistralmente (Müller. 1980; Ramírez, 1969; Gow, 1974; Flores Ochoa, 1990, etc.). Trataremos, por el contrario, de analizar los elementos culturales y la lógica que hoy como ayer se siguen constantemente practicando, por más que se vea y se hallen aspectos modernizantes (Poole, 1988).

Para comprender la lógica subyacente de la cultura indígena andina en la peregrinación, desentrañaremos los elementos representativos, por ser parte esencial de la cultura, y la cultura se basa fundamentalmente en el manejo de significaciones y un significado hace que la cultura dependa de este; es decir, toda cultura depende del símbolo, pues sin ćl no hay cultura. La representación diferencia al humano de los animales, por esta razón, el símbolo es la unidad básica de toda conducta humana que se origina en el uso de modelos o arquetipos con propósitos de encarnación.

"Fue el símbolo el que transformó a nuestros antepasados antropoides en hombres y los hizo humanos. Todas las civilizaciones han sido generadas, y son perpetuadas, sólo por el empleo de símbolos. Es el símbolo el que transforma a un infante de homo sapiens en un ser humano: toda conducta humana es conducta simbólica;

1. Se han escrito varias investigaciones sobre esta peregrinación, e incluso existe un debate sobre la verdadera denominación y significado, así tenemos que comúnmente se denomina "QUYLLUR RIT'I" cuyo significado sería "estrella de nieve". (Flores, Carlos: 1987; Marzal: 1971; Gow: 1974; Sallnow: 1974; Ramírez: 1969; Müller: 1980; etc.) Mientras por otra parte se indica que la denominación correcta es "QOYLLLRIT'I" que significa "nieve blanca inmaculada y resplandeciente" (Flores Ochoa, J:: 1990: 76-78). 
la conducta simbólica es conducta humana. El símbolo es el universo de la humanidad." (White, 1964: 41).

Para las diferentes culturas, como la indígena andina, una representación es un valor o significado adjudicado por los usuarios y este puede tener cualquier forma fisica (de un objeto, sabor, olor, etc.), de lo contrario, el símbolo no penetrará en la experiencia humana. El significado de un símbolo no se puede descubrir o analizar con un simple examen sensorial de su forma física, pues trasciende a ella. A estas representaciones culturales Jung las define como:

“[..] un nombre o aun una pintura que puede ser conocido en la vida diaria aunque posea connotaciones específicas además de su significado corriente y obvio. Representa algo vago, desconocido u oculto para nosotros [...] una palabra o una imagen es simbólica cuando representa algo más que su significado inmediato y obvio. Tiene un aspecto 'inconsciente' más amplio que nunca está definido con precisión o completamente explicado." (Jung, G., 1984: 17-18)

\section{ELEMENTOS SIMBÓLICOS}

En Quyllur Rit'i se ve permanentemente la concurrencia de elementos simbólicos, como la piedra, la nieve (apu) y el agua. Sobre estos elementos de la naturaleza condensan significados socialmente compartidos con la visión cosmocéntrica de los runas indígenas andinos hasta cobrar ribetes deificantes que expresan evidentemente un origen andino.

Este sistema de representaciones configura su identidad, crea nexos entre sus miembros, y las distingue de otro tipo de cultura o sociedad.

\section{a. La piedra}

La piedra en la cultura indígena andina tiene múltiples significados, ya que este es la base de sus representaciones, desde lo sagrado y mítico hasta las actividades de juego que los niños indígenas andinos practican.

Las piedras fueron incluso consideradas como elementos con vida y con facultad de hablar. Mama Huaco hacía hablar a las piedras, "... esta dicha señora hacia hablar a las piedras y peñas idolos y huaca." (Guamán Poma, 1993: 96).

Mitológicamente la petrificación es un proceso presente en una gran cantidad de narraciones indígenas andinas, de diferentes lugares y con una infinidad de hechos y tramas, a modo de perennizar o testimoniar el magno acontecimiento, que todos los miembros o runas de la cultura indígena andina deben recordar. Por esta razón la piedra es la representación simbólica de personas y héroes míticos de indígenas andinos que en un momento fueron seres vivos y que luego sufren una trasmutación al petrificarse. Todos estos hechos muestran a la piedra como elemento con vida y movimiento tan igual como los runas y receptáculo de saberes de hechos sagrados. La piedra significa en la cultura indígena andina, eternidad, seguridad, dureza, y equilibrio. Este mensaje aquí expuesto enfoca todo un concepto. La piedra es consustancial a la cultura indígena andina, este elemento lítico fue utilizado para perennizar los mensajes simbólicos y dejar a la posterioridad conceptos de su saber, en estricto orden lógico y solo comprensible por miembros de esta cultura, que muestran deseos de ser cada vez más perfectos en su comportamiento ético.

La piedra en el juego que los niños indígenas andinos practican, asume también aspectos simbólicos; por ejemplo en la zona de Llalli, Melgar, Puno, los niños buscan en la orilla de los ríos, piedras cristalinas de diferentes colores y de diferentes tamaños, sus colores varían desde blancas cristalinas, hasta azuladas, grises, amarillas y coloradas intensas; hallar una de estas piedras genera gran alegría para los niños porque simboliza animales, en este caso vacunos [waka significa res o vacunos en general]; cada niño va armando así lo que ellos denominan como su mahada o rebaño de vacas, con las que juega recreando el pastoreo y la reproducción, ya que el padrillo es una piedra de las mismas características pero de mayor dimensión; es decir, la más grande que tiene en el conjunto de piedras, mientras más grande sea será la representación de los toros "brunsis" [Brown Swiss].

Esta práctica parece que no es exclusividad del medio observado, pues tomemos en cuenta el siguiente dato etnográfico de David Gow, en función a la piedra:

"El primero de agosto, que es el día en que la tierra o Pachamam vive, para buscar un recuerdo de los Apus. Estos recuerdos toman la forma de pequeñas piedras en forma de vacas, cerdos, caballos o alpacas, dependiendo de la estrella o fortuna de los que las encuentran y se las conoce como inkaychu [inqaychu]. Alguna gente nace para criar ovejas y otras para criar vacas. A veces se encuentran estas piedras con dos cabezas finamente formadas. Con frecuencia son blancas o grises, pero a veces son negras. Son bendecidas en la misa, rociadas con agua bendita y de esta 
forma sirven para curar las enfermedades de las alpacas y de esta forma sirven para el viento. Se las lleva durante los viajes para cuidarlos de los malos espíritus o de las almas. Puesto que son un presente del $A p u$ Ausangate participan de sus características y poderes; por ejemplo, no les gusta ser vistas y transpiran cuando alguien lo hace. Estas piedras también pueden ser encontradas en las entrañas de los animales que son beneficiados el primero de agosto. Sin embargo se considera que los inkaychu son un don de la Pachamama." (Gow, 1975: 146-147)

El cosmos andino es una totalidad orgánica y Kusch afirma que el centro de este cosmos orgánico no está en el yo de cada uno, sino en un lugar ignoto que a veces se puede visualizar transitoriamente en la piedra tocada por el rayo o en algún lugar sagrado, y en torno a él gira lo viviente (Kusch, 1971: 394).

La piedra como elemento de representación simbólica ya se visualiza desde Chavín de Huántar, que es un lugar que se encuentra en el corazón de los Andes, sobre una terraza aluvial relacionada con el río Pukcha o Mosna.

En una de las galerías principales del viejo templo se encontraba la gran imagen de un ídolo tallado en piedra, conocido como lanzón. Y al estilo de este tallado, en toda la cultura andina, se pueden hallar glifos andinos de diferentes formas y tamaños en los centros ceremoniales.

La concepción de la piedra que tiene el indígena andino aún va más allá, cuando consideran a las cosas "inanimadas" como miembros que forman parte del ayllu como si fueran personas vivas tan iguales a ellos. "Mejor seria decir que para los componentes del ayllu no existen las cosas "inanimadas". Una piedra o la tierra es un organismo que crece, que tiene también una vida elemental. Escuchemos estas opiniones de Grimaldo:

"En el mundo andino todo es vivo e importante; nada es inerte y nadie sobra. La piedra misma es viva, habla y el campesino conversa con ella de persona a persona. Unas breves frases sobre lo vivo que son las piedras, en palabras de don Carlos Olivares y de don Javier Huamán Lara, campesinos cajamarquinos nos ayudarán a comprender lo que afirmamos:

"Nuestros antiguos decian que el chungo (del quechua Chunku/ ch'unku = piedra) tiene vida, crece, que eran nuestros idolos. $Y$ sí, es cierto. Hará unos 5 o 6 años mi viejo se habia encontrado un chungo y todos le dïjmos que lo vuelva a enterrar donde estuvo. Después de un tiempo lo volurimos a sacar y ya estaba más grande[...] cuando lo volvimos a sacar al chungo y lo pusimos a otro lugar ya no creció más[...] Si encontramos una culebra y cogemos una piedra para matarla, es dificil, a veces ni

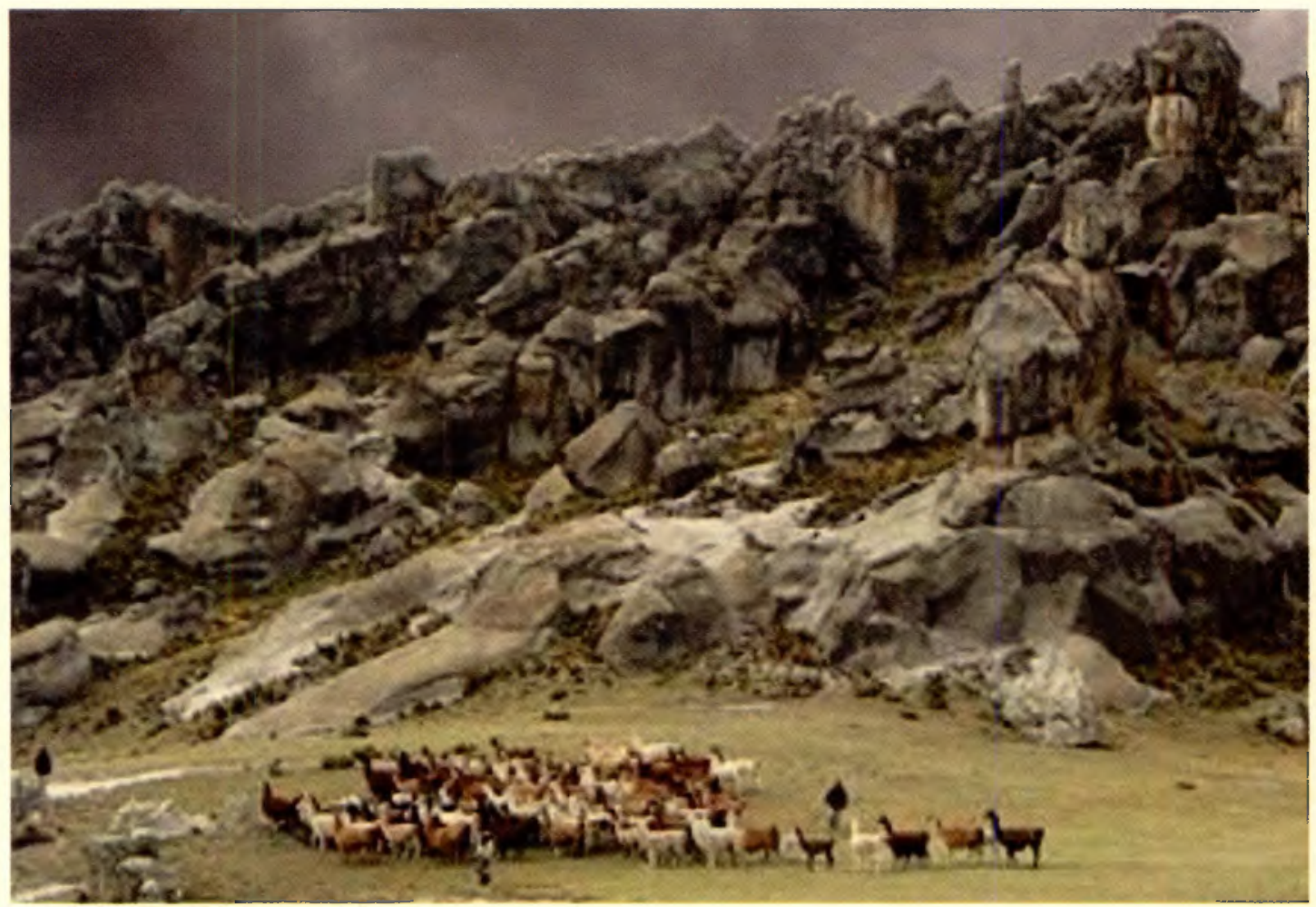

Wayllay en Cerro de Pasco; Foto de Marcos Fernández 


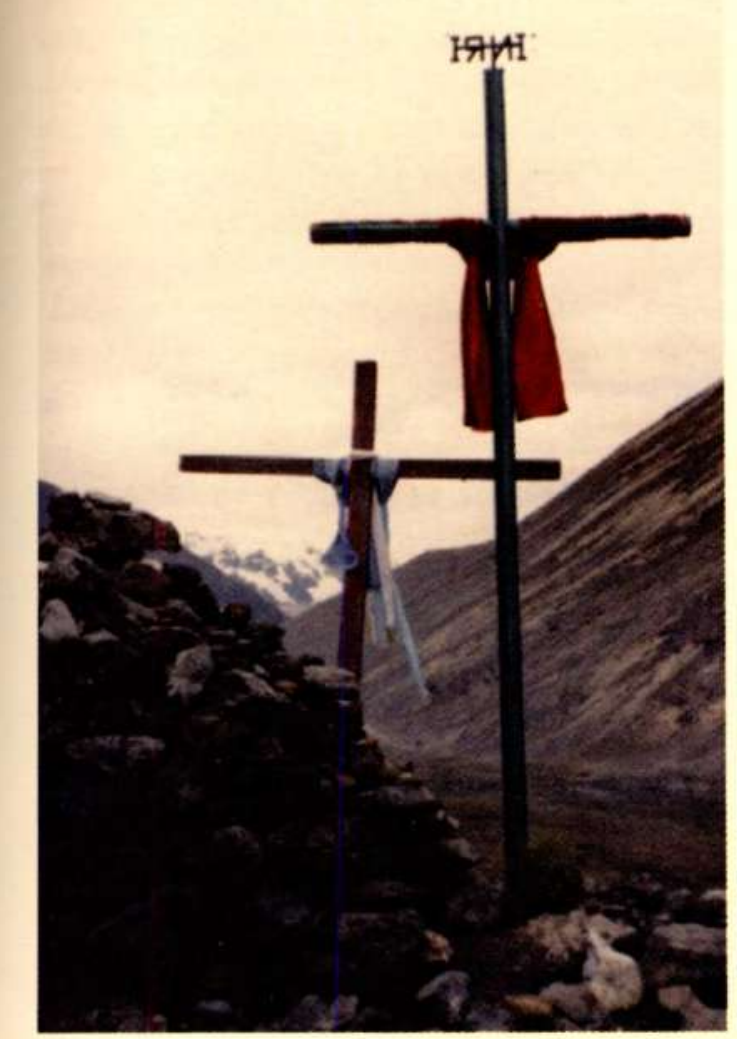

En esta vista se puede observar los dos elementos simbólicos de la fe religiosa: la andina basada en la piedra Apachita, y la cruz occidental de madera. (Foto: $E$ : Cáceres: 2001).

lo alcanzamos [...] Por eso dicen que las piedras son sus familias de las culebras y de las lagartijas."

(Rengifo, Grimaldo: Comunicación personal; 2011 en Cusco-Perú)

Ahora, los Andes están traspasados por paisajes en los que la piedra es el elemento central del panorama natural, como presentadora y modeladora de imágenes de dimensiones considerables, con las que alimenta, a modo de materia prima, los diferentes mitos de los runas indígenas andinos. Evidente que estos lito-morfos, que son formaciones modeladas pacientemente por los fenómenos naturales (lluvias, tempestades, etc.), y por la misma naturaleza (agua, viento, fuego, etc.); como los bosques de piedra de Wayllay en Cerro de Pasco que están a $4.300 \mathrm{msnm}$, en los que se puede observar nítidamente una alpaca comiendo pasto. (Simantirakis,: 2008), y también se puede hallar en varias zonas andinas, como los Fraylones en Cajamarca, Huayanay en
Huancavelica, Marcahuasi en Lima, Tinajani en Melgar-Puno, Tres cañones de Suyk'utambu, Cusco, entre otros.

Por todas estas consideraciones, la piedra es un elemento importante en el culto prehispánico. Hoy igual que ayer, los runas andinos la siguen utilizando, como se puede apreciar en la construcción de casitas y bienes aspirados, dentro del marco de un juego simbólico de premonición, deseo y aspiración. Asimismo, la roca en las que se dibujó el Taytacha Quyllur Rit'i, sigue marcando el punto de referencia central del espacio sagrado de esta peregrinación, pese a que se intentó utilizar la madera de Tayanca como elemento central para la cristianización. Sobre este tema, el pintor cusqueño Fabián Palomino, que pintó al Señor de Quyllur Rit'i nos refiere así:

“Hasta 1917 el Señor de Sinakara [Sinaq'ara] se adivinaba apenas en el gran farallón. Los indios habían levantado una choza para protegerlo y decían que estaba ahí. Los viejos taytas contaban que en épocas lejanas hubo una cacería humana, un chaku para coger a un niño dios que jugaba con un pequeño llamerito... miles lo persiguieron y el Cristo se estampó primero en un árbol de Tayanka, después se dibujó en la roca de los dioses incas, a un metro del nevado. El pastorcito corrió hasta él desesperado y golpeó la piedra llorando, diciendo que ahí estaba su niño clavado en una cruz, no dijo más porque la pena hizo estallar su corazón." (Fabián Palomino en Caretas, texto reproducido en la edición de la revista Ausangate $\mathcal{N}^{\circ}$ 1: Ocongate, Quispicanchi-Cusco; 1991).

Este aspecto es analizado por David Gow (1974: 53-27). Así mismo, la piedra marca los puntos de referencia para los descansos en forma de apachitas ${ }^{2}$. En los $8 \mathrm{~km}$ de subida de Mahuayani a Sinakara, donde se halla el santuario, existen quince apachitas y quince cruces, es decir la piedra andina y la madera del cristianismo, se les presenta a los peregrinos en forma paralela, pero nunca fundida ni unida.

A partir de la mitología andina del origen del santuario, se puede diferenciar los elementos que el niño cristiano busca para el refugio. Primero, como buen cristiano, busca el árbol de tayanka [madera]; luego, cuando este no es seguro recurre a la piedra andina, y quien percibe con claridad el recorrido es el niño andino, a quien, por su cosmovisión, la

2. Las Apachitas son montículos de piedra donde el peregrino o el viajero hace su ofrenda para recobrar fuerza o energía y proseguir su camino en completa tranquilidad y armonía. Un viajero, cuando se aproxima a una apachita, busca en los alrededores una piedra que puede tener un volumen considerable, la que cargará hasta el montículo y alli depositará como quien deja su cansancio, penas, dolores, problemas y dificultades. 
piedra se le presenta como el último refugio del Seños por ser permanente, sólida y eterna, superior a la madera en estas bondades. Este aspecto nos demuestra un deslinde de los materiales en los que se representan las dos religiones. La cristiana fundamentalmente es representada por la madera y la religiosidad andina basa sus símbolos sagrados en la piedra.

Las representaciones en piedra son registros visuales que apoyan a la lengua hablada en culturas orales y ágrafas, porque son sistemas de signos semióticos que representan una información o código simbólico.

Las piedras fueron usadas por los indigenas andinos no solo como elementos simbólicos rituales, sino también en la construcción de sus viviendas y sus palacios. La arquitectura andina se desarrolló basándose en la piedra, porque fundamentalmente expresa sencillez, simetría y seguridad.

La piedra tiene utilidades en la articulación de relaciones de amistad y comunidad. Así tenemos por ejemplo que en las comunidades de Sibayo, provincia de Cailloma en las partes andinas de Arequipa, existe una roca denominada piedra de la amistad, la forma de la roca es que tiene un hoyo o agujero que pasa de un extremo al otro y en ambos extremos hay una especie de asiento o espacio para arrodillarse. Los enemigos o contrincantes se ubican a ambos lados del hoyo y meten el brazo derecho al agujero hasta encontrarse con la mano del otro runa, y en media roca se dan la mano. Este acto sella la amistad y disipa las diferencias. Seguidamente, ambos se encuentran en forma directa y reafirman su acto de amistad con un abrazo ritual de dos tiempos con el sombrero en la mano, disipando las diferencias; es decir, cumplen con el pampachasqa. Esta forma de rearticular comunidad parece haber sido una práctica de la cultura Kollaguas ${ }^{3}$.

\section{b. NEVADO 0 APU: Expresión de la Ruta Cultural del Agua.}

El agua tiene un recorrido desde las entrañas de la tierra, Ukhu Pacha o mundo de adentro o el subsuelo, pasando por la superficie de la tierra Kay Pacha, este mundo o mundo de aquí, hasta el Hanaq Pacha, mundo de arriba, formando en el cosmos una via láctea perceptible desde el Kây Pacha, de la que retorna nuevamente al kay Pacha en forma de para, chikchi, y riti, lluvia, granizo y nieve, respectivamente, a modo de un fluido permanente y eterno que va circulando sin detenerse. Esta ruta cíclica es representada simbólica y dinámicamente por el k'uychi, arco iris.

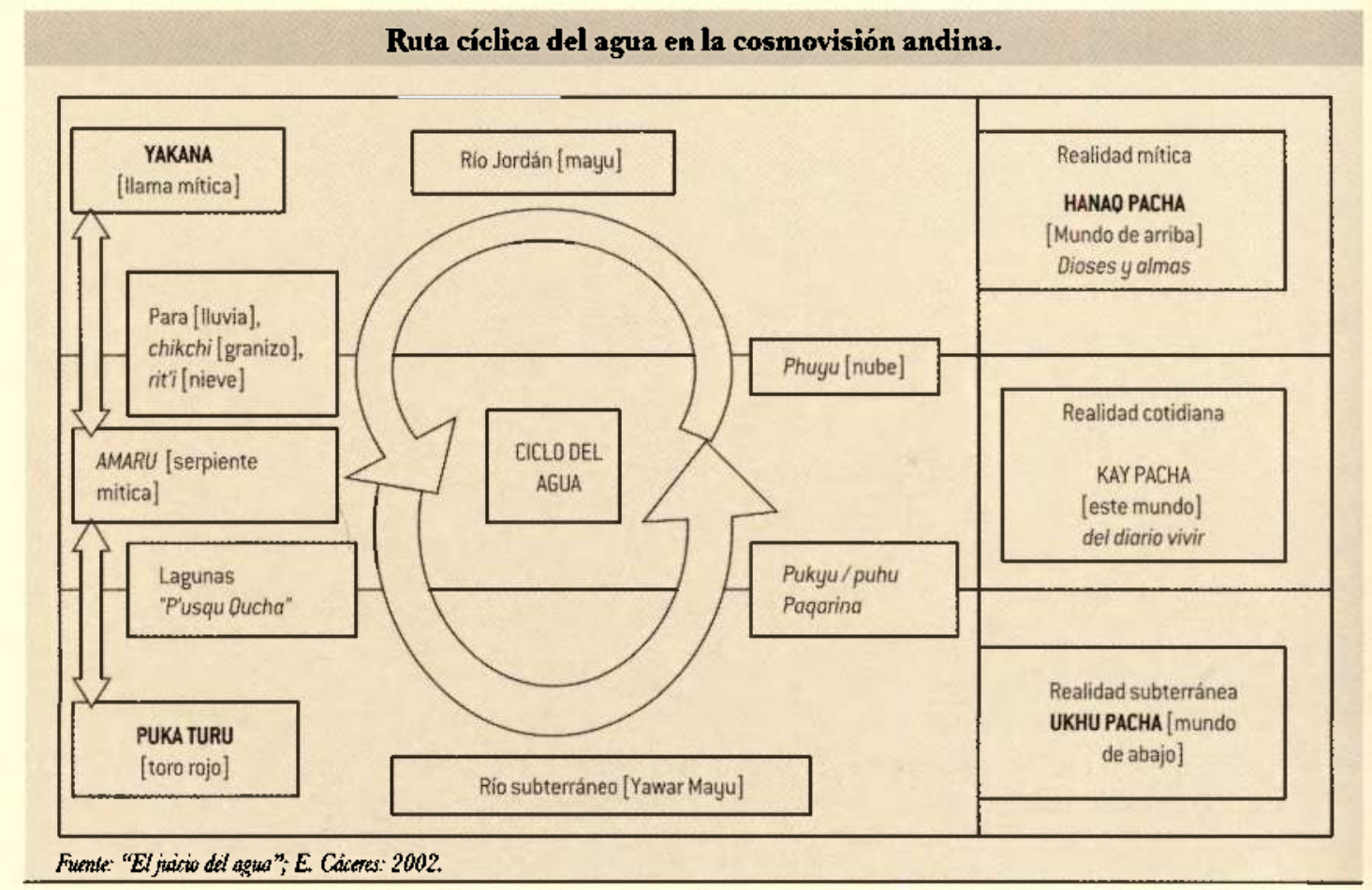

3. Informante: Adencio Pichas, natural de Sibayo, Guía de Turismo. Información recogida por el autor, en febrero de 2006. 
El estricto cumplimiento de este recorrido es vital para la existencia de toda forma de vida en el cosmos. El detenimiento, en su forma de vida y movimiento, trae consigo grandes desequilibrios de carácter escatológico de dimensiones cósmicas.

La visión cíclica del tiempo en la crianza del espacio andino se percibe también en la ruta cultural recorrida por el agua. Porque la percepción de los runas muestra en esta ruta el movimiento circular y cíclico, a modo de un eterno y constante movimiento circular en la que expresa dinamismo y vida. Es bastante conocido que esta visión cíclica se inspira en el ciclo agrícola y climático, vegetativo, inscrito en el calendario ceremonial y ritual que determina la actividad de los runas andinos, de forma directa o indirecta, formando una estructura conceptual alrededor del cual se organiza la mitología y la cosmovisión. Idea también expresada por Makowski en Hocquenghem (1987).

En este movimiento cósmico el agua cumple diferentes funciones, desde roles benéficos de reproducción, generación y traslación de vida, hasta roles maléficos, de destrucción de la humanidad mediante cataclismos de niveles cósmicos, como los narrados en los diferentes mitos andinos como el "Unu Huishu" juicio del agua; es decir, genera la muerte. La ruta del agua por lo tanto, recorre las dos dimensiones de expresión de la existencia: vida y muerte, como una dualidad permanente que se engarza en el tiempo y en el espacio cósmico de los andinos. Aspecto que se percibe a partir de los detalles narrados y practicados por los runas de nuestros tiempos.

El agua por lo tanto, recorre diferentes espacios, niveles yórdenes: órdenes de la naturaleza animada, cósmica y social, a modo de un elemento articulador, al mismo tiempo fijador y regulador de todo cuanto existe en el cosmos andino. El agua como símbolo de inserción articula todo lo que se opone y complementa.

En este recorrido, el agua forma los nevados que vienen a ser reservorios naturales de los andinos usados para el riego de sus chacras. Por lo tanto, al solidificarse el agua en las montañas cobra dimensiones de deidad andina del Kaypacha, que también es un elemento simbólico que expresa sacralidad y que los ukukus o pawluchas integran permanentemente al contexto ritual sagrado de Quyllur Rit'i. Los paweluchas o ukukus son considerados los agentes articuladores de lo humano y lo sagrado en la conciencia del andino. Por cuanto la población, al explicar sobre su origen, refiere que son Semi-Dioses y Semi-humanos, son los hijos predilectos del Apu Ausangati o del señor de Quvllur Rit'i. Ahora bien, ¿qué representa el ukuku? Esta interrogación genera polémica pues para algunos representa al oso andino (Gow, Carlos Flores, etc.).

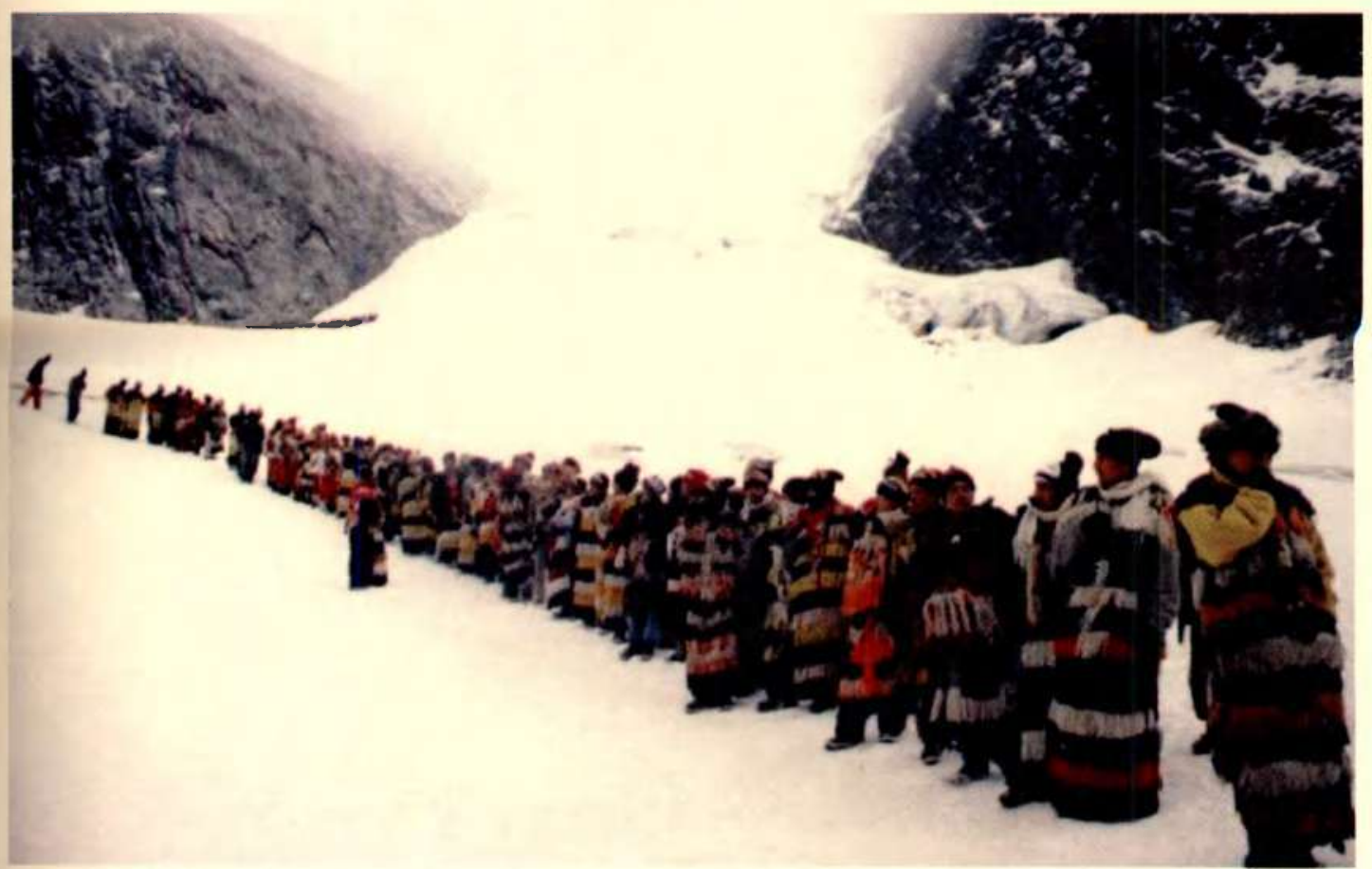

Los apus [nevados], deidades del panteón religioso indigena andino, son dioses de altura, y Quyllur Rit'i es una de las más emblemáticas. (Foto: E. Cáceres: 200I). 
Según otros estudiosos, representa a la alpaca o en todo caso a los camélidos sudamericanos (Flores Ochoa, 1990).

\section{c. EL AGUA: Rol purificador del agua en los Santuarios Andinos.}

En los espacios sagrados andinos como los santuarios siempre cuentan con manantiales de agua, sacralizados por los runas. La ubicación de estos también es estratégica en función a la ruta principal de acceso al templo o local sagrado en donde se halla el Señor.

Por lo general se encuentran a cierta distancia antes de llegar al Señor, así por ejemplo que primero se llegue directamente al templo sin pasar por el manantial o fuente de agua sagrada, o Agua del Señor.

Estas ubicaciones tienen un fin primordial, el de que antes de llegar a ver al Señor uno debe lavarse para llegar limpios, K'acha. Esta limpieza no tenemos que entenderla solo en el contexto de higiene corporal, sino también en el plano espiritual. Quien se lava en estas fuentes, al mismo tiempo se está purificando para poder ser recibido favorablemente por el Señor, porque el runa mostrará su alma y su cuerpo en forma cristalina, ch'uya, como el agua de la fuente.

Esta práctica también se repite en los ritos mortuorios, pues se lava al cadáver para que se presente ante dios limpio de pecados, k'acha. (Santa Rosa, Melgar, Puno, 1995: observación personal).

Por esta razón, las aguas de las fuentes de los santuarios de Huanca y Quyllur Rit'i son sagradas y medicinales, incluso serán transportadas en pequeños depósitos al lugar de origen de los peregrinos andinos.

El agua como elemento de la salud se manifiesta de diferentes formas como los bloques de hielo del nevado cargados por los ukukus o pawluchas que luego son usados con fines medicinales (Flores, C., 1987; Flores, J., 1990), cumpliendo así uno

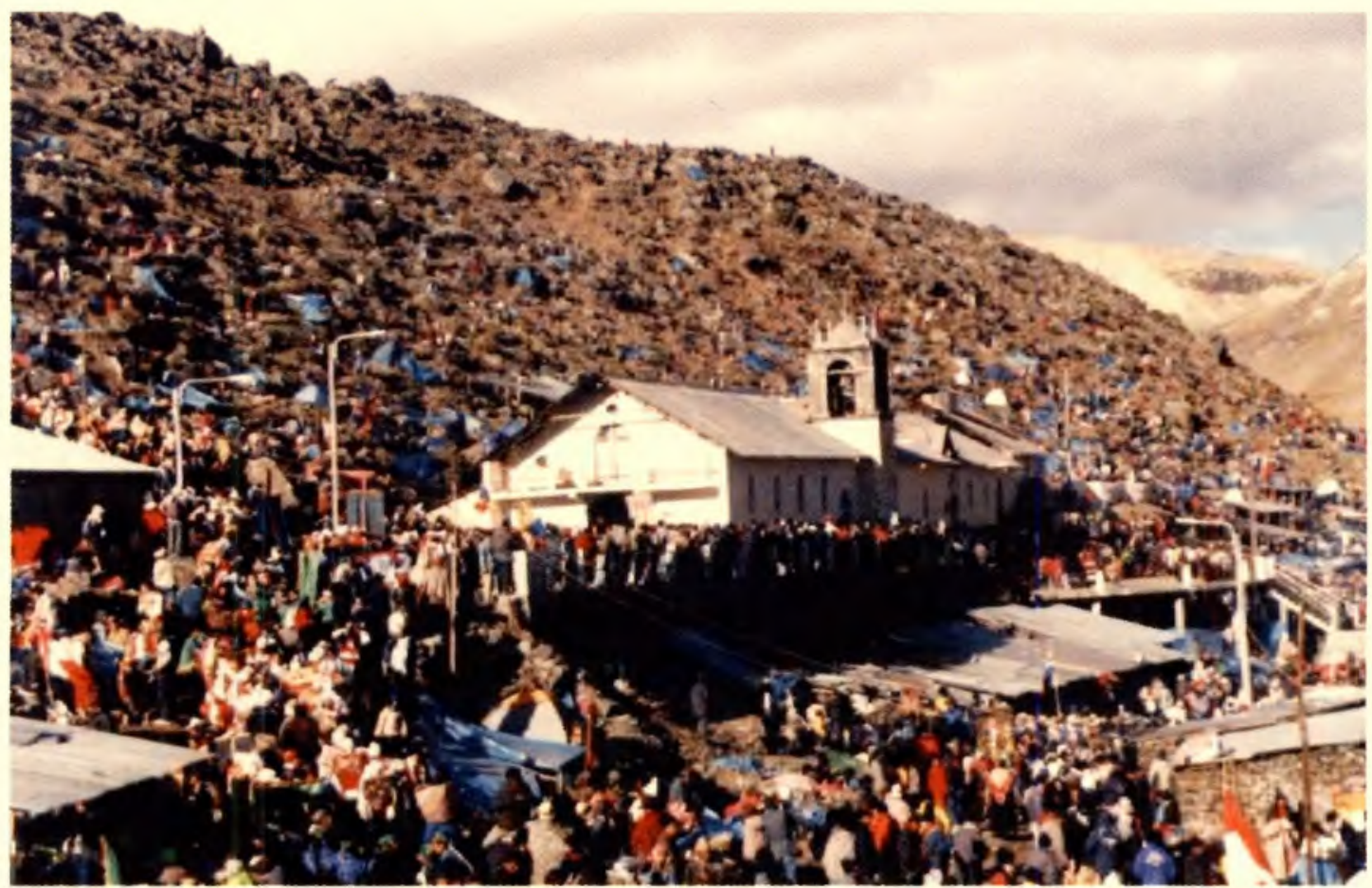

Templo del Señor de Quvylur Rit', en plena misa de fiesta. (Foto: E. Cáceres, 2001).

Fiunte: "El juicio del agua"; E. Cáceres: 2002. 
de los objetivos de la peregrinación andina por quienes buscan en el Santuario salud y bienestar para ellos y sus bienes, reproducción de sus animales y demás bienes para su subsistencia.

Por lo tanto, el agua es otro elemento que funciona como símbolo de purificación, así como también tiene el don de dar buena salud o, de lo contrario, sirve como remedio para las enfermedades. La concepción andina de recuperar la salud y restaurar la vida está relacionada con la ética y el perdón del pecado (Cáceres, 1990). Asimismo, el lugar de la fuente está a la entrada del Santuario y que como paso obligado el peregrino utiliza para lavarse con el agua del Señor antes de presentarse a él; ésta es una lógica andina que se usa también en los ritos mortuorios: hay que bañar el cuerpo del difunto para que se presente limpio sumaq o k'acha ante Dios. Esta lógica se percibe aún en esta peregrinación como continuidad y resistencia del pensamiento andino.

En conclusión, estos tres elementos: piedra, nieve y agua, que intervienen en la peregrinación del Señor de Quyllur Rit'i, son depositarias de un hecho psicológico muy conocido en donde un individuo puede tener tal identidad inconsciente con alguna otra persona u objeto. Recordemos la propuesta de Carl Jung:

“[...]en nuestra experiencia diaria necesitamos decir cosas con la mayor exactitud posible, y hemos aprendido a prescindir de los adornos de la fantasía en el lenguaje y en los pensamientos, perdiendo así una cualidad que es aún característica de la mente primitiva. [...] el primitivo sigue dándose cuenta de esas propiedades psíquicas; dota a animales, plantas o piedras con poderes que nosotros encontramos extraños e inaceptables." (Jung: 1984: 39).

\section{Bibliografía}

BURGA, Manuel

1988. "La utopia y el sentido común". En: "Márgenes, Encuentro y Debate". Ed. Sur, Casa de Estudios del Socialismo $\mathrm{N}^{\circ} 4$. Lima- Perú.

\section{CÁCERES, Efraín}

1988. "Quyllur Rit'i: Realidad que exige compromiso", en "Márgenes, Encuentro y Debate". Ed. Sur, Casa de Estudios del Socialismo $\mathrm{N}^{\circ} 4$. Lima- Perú.

1989. "Dioses que Cuidan la Salud, Carácter de la Religiosidad en la Medicina Andina".

En. Cuadernos Qhalikawsay. Ed. CMA-Cusco.

2002. "El Juicio del Agua 'Unu Huishu': Simbolismo y Significado Ecológico del Agua en Mitos Andinos, 'El Milagro de la Laguna Salada' de Musuq Llaqta”. En: Ed. ABYA YALA - CICTA; Quito - Ecuador.
Estehechosolo está expresandolaidentificación y extensión de su yo psicológico y corporal de los runas andinos con la naturaleza a la que siempre vieron como su madre y protectora Pachamama.

Entre los tres elementos el que cobra mayor relieve es la nieve, rit'i. Es por esta razón incluso que se elige el espacio sagrado, por su topónimo de Quyllur Rit'i, aun cuando existe otro nevado o Apu como el Ausangati, de mayor jerarquía en la lógica de los andinos. Al hacer una simple observación, pareciera que allí se va expresando la lógica tríadica del runa andino, a modo de una santa trinidad que conjuga incluso el estado ideal de su propuesta utópica. O sea que entre los dos elementos extremos que son piedra, sólido, y agua líquida, la nieve, rit'i, es el estado ideal que amalgama y articula los desencuentros; es el elemento que fisicamente se halla como intermedio o centro, chaxpi, como manifestación del encuentro de los dos extremos, que solos podrían presentarse como estados peligrosos o patológicos, porque generan desequilibrios de todo orden, incluso cósmico.

Como se puede observar, a modo de conclusión, hallamos en esta peregrinación los elementos simbólicos que juegan un rol fundamental, circunscritos muy bien a la lógica $y$ al pensamiento andino; lógica y pensamiento que se recrean y resisten hasta la actualidad en la peregrinación de Quyllur Rit'i. Aun cuando cambian las formas, el contenido persiste. Este aspecto nos estaría mostrando la presencia de un verdadero arquetipo de la cultura andina, entendiendo por arquetipo la tendencia a formar tales representaciones en las que pueden variar muchísimo los detalles, pero no se pierde el modelo básico cultural.

\section{FLORES, Carlos}

1987. "El santuario de Quyllur Rit'i (una peregrinación andina), expresión y germen de organización campesina". En: Antropológica, Ed. PUCP-Perú.

\section{FLORES, Jorge}

1990. "Taytacha Quyllurit'i el Cristo de la Nieve Resplandeciente". En: "Cuzco, Resistencia y Continuidad". Ed. CEAC - CONCY'TEĆ; Cusco.

\section{Gow, David y Rosalinda Gow}

1975. "La Alpaca en el Mito y el Ritual". En: Allpanchis Nog. [141 - 174] Ed. IPA. Cusco.

\section{GOW, David}

1974. "Taytacha Quyllur Rit'i. Rocas y bailarines, creencias y continuidad". En: Allpanchis No7. Ed. IPA. Cusco. 
ReVista UniversitaRIa 141

GUAMAN POMA DE AYALA, Felipe

1993. Nueva Coronica y Buen Gobierno. Lima, Ed. Fondo de Cultura Económica.

JUNG, Garl

1984. El Hombre y sus símbolos. Barcelona, Ed. CARALTBUC.

\section{KESSEL, Juan Van}

1988. "Quyllur Rit'i: el milagro que escapó al antropólogo y la caja vacía de estructuras". En: "Márgenes, encuentro y debate". Ed. Sur, Casa de estudios de socialismo $\mathrm{N}^{\circ} 4$. Lima.

KUSCH, Rodolfo

1971. "Pensamiento Aymara y Quechua". En: América Indigena Vol. XXXI, $\mathrm{N}^{\circ} 2$; México.

\section{RAMÍREZ, Juan Andrés}

1969. "La novena al Señor de Quyllur Rit'i". En: Allpanchis $\mathrm{N}^{\circ}$ l. Ed. IPA-Cusco.
MÜLLER, Thomas

1980. "El Taytacha de Quyllur Rit'i'. En: "Pastoral Andino"; $\mathrm{N}^{\circ}$ 32; Ed. IPA-Cusco.

PIÑA GHAN, Román

1993. El Lenguaje de las Piedras glificas Olmeca y Zapoteca. México, Ed. Fondo de Cultura Económica.

\section{POOLE, Deborah}

1988. "Quyllur Rit'i: realidad que exige compromiso". En: "Márgenes, encuentro y debate". Ed. Sur, Casa de Estudios del Socialismo $\mathrm{N}^{\circ} 4$. Lima- Perú.

\section{SALLNOW, Michel}

1974. "La peregrinación andina". En: Allpanchis N7. Ed. IPA. Cusco.

\section{SIMANTIRAKIS, Vasilis}

2008. Una Mirada al Perú Pétreo. Lima, Ed. DDK

\section{WHITE, Leslie A.}

1964. La Ciencia de la Cultura: Un Estudio del Hombre y la Civilización. Buenos Aires, Ed. PAIDOS. 